\title{
How can New Zealand schools respond to climate change?
}

RACHEL BOLSTAD

\section{KEY POINTS}

- International climate agreements say education has a key role to play in responding to the climate crisis, but current national education policies don't provide clear direction about what this means for schools.

- Many New Zealand schools report that they support student leadership around environment and climate issues, but school-wide approaches to climate and sustainability are less common.

- In classrooms, students have opportunities to learn about climatechange causes and impacts, as well as personal actions they can take to make a difference.

- Students have fewer opportunities to engage in collective and systemic actions, or learn about career pathways and opportunities in a lowemissions economic future.

- System changes on the horizon, both within and beyond education, could generate opportunities for more coherent system-wide educational response to climate change. 
International climate agreements say education can play a key role in responding to the global challenge of climate change. My team and I are currently carrying out research to help build a national picture of educational responses to climate change. Our research suggests that New Zealand's educational policies and strategies currently provide a diffuse framework for responding to climate change, and there is a lack of coherent messaging "from the top" about what could or should be expected of schools. Yet some innovative practices and approaches are visible across the school network. This article describes what we currently know about climate and sustainability thinking and practice across English-medium schools, and what further actions and supports may be needed across the system.

\section{Introduction}

Climate change is already affecting Aotearoa New Zealand, and we can expect a variety of ongoing and future impacts (Ministry for the Environment, \& Stats NZ, 2020). Human industrial and agricultural practices are increasing volumes of greenhouse gases (GHG) in the atmosphere, leading to more of the sun's energy being retained on the planet as heat. Public surveys suggest New Zealanders are concerned about climate change (Leining \& White, 2015) and think more action is needed (IAG, 2020). Shifting national and global systems from high-emissions to low- and zero-emissions is necessary to ensure a safe climate future, but making these changes is not straightforward owing to conflicting economic, political, and social interests.

Just as the causes of climate change are complex, so too are its impacts and effects. Climate change poses a challenge to political leaders, policymakers, and leaders within every sector, requiring traditionally separate issues to be addressed in an interconnected manner (UNESCO, 2015). Scientific consensus provides a clear signal about the urgency of action required. ${ }^{1}$ The next few years represent a short window within which the global community can take action to mitigate the severity of climate-change impacts by reducing net GHG emissions, and supporting nations and communities to adapt and be resilient to impacts that will happen as a result of climate change. ${ }^{2}$

My team and I are currently carrying out research to help build a national picture of educational responses to climate change. Our first year of datagathering has focused on New Zealand English- medium schools. The data we have collected include national surveys of primary/intermediate (Bolstad, 2020a) and secondary/composite schools (Bolstad, 2020c); in-depth interviews with people who bring different perspectives including youth, educators, Māori, Pacific New Zealanders, and people with an academic/policy/system perspective (Bolstad, 2020b). In this article I consider the extent to which school education in New Zealand is fulfilling its potential to contribute towards ensuring a safe climate for the future, and what further action and supports may be needed.

\section{New Zealand's commitments to the global climate challenge}

Since the early 1990s, New Zealand has been a Party to The United Nations Framework Convention on Climate Change (UNFCCC),3 an international environmental treaty whose objective is to "stabilize greenhouse gas concentrations in the atmosphere at a level that would prevent dangerous anthropogenic interference with the climate system" (United Nations, 1992 , p. 4). Parties meet at annual Conferences of the Parties (COP) to assess progress. In December 2015 at COP21 a landmark agreement (The Paris Agreement) was reached to accelerate and intensify the actions and investments needed for a sustainable, low-carbon future, aiming to "bring all nations into a common cause to undertake ambitious efforts to combat climate change and adapt to its effects". 4 The Paris Agreement requires that all Parties report regularly on their emissions-reduction and implementation efforts. In late 2019, New Zealand Government passed the 
Climate Change Response (Zero Carbon) Amendment Act, 5 which sets out new emissions-reduction targets and other plans and measures to keep New Zealand on track to deliver on its climate commitments.

\section{Education's role in the global climate response}

Globally, education is seen as playing a central role in responding to climate change, "by enabling society to be a part of the solution". ${ }^{6}$ Article 6 of the UNFCCC (United Nations, 1992) outlines the need for "education, training, and public awareness" initiatives with respect to climate change, and these are reported on in New Zealand's required four-yearly National Communication reports to UNFCCC. In the last National Communication (Ministry for the Environment, 2017), the 22-page section on education, training, and public awareness includes just one page describing activities related to school-sector education. The report notes that "there are opportunities to learn about climate change and sustainability issues across many areas and year levels of the curriculum" (Ministry for the Environment, 2017, p. 305), and that government "provides resources and funds programmes to facilitate and encourage environmental education in schools". The work of the Toimata Foundation, providers of the Enviroschools (English-medium) and Te Aho Tù Roa (Māori-medium) programmes, is also mentioned.?

The next National Communication report, due in 2021, may discuss recent developments such as a $\$ 5$ million Sustainability Contestable Fund, launched in 2019, "to support schools to reduce their environmental impact and improve their operational efficiency", ${ }^{8}$ and new teaching and learning resources published on TKI such as the 2020 Climate Change Learning Programme ${ }^{9}$ (see Eames et al., 2020, for a review of the programme) and Pütätara, a resource focusing on sustainability and global citizenship. ${ }^{10}$ Though these pockets of activity are positive, and provide more tools for schools, climate change is barely visible in most current Ministry of Education policy and strategy documents, ${ }^{11}$ with a few exceptions. The 10-year school property strategy (Ministry of Education, 2020a) doesn't directly mention climate change, but does comment on "opportunities to demonstrate approaches to reducing emissions" (p. 20). The recent Action Plan for Pacific Education mentions climate change once, encouraging schools to "celebrate and value Pacific success in learning environments, including community contributions that are relevant such as Pacific youth fighting climate change" (Ministry of Education, 2020b, p. 32). The strategy for international education also mentions climate change once, saying that "we need to be global citizens so that we can tackle global issues of the 21st century, such as sustainability, globalisation and climate change" (Ministry of Education, 2018, p. 22). This seems to be a stronger iteration of an older statement from the "principles" page of The New Zealand Curriculum (Ministry of Education, 2007, p. 9) which did not specifically mention climate change, and framed these as "future-focused" issues". ${ }^{12}$

One cross-sectoral strategy and action plan ${ }^{13}$ which is not visible on, or linked to from, the Ministry of Education website is Mätauranga Whakauka Taiao: Environmental Education for Sustainability (Department of Conservation, Ministry for the Environment, and Ministry of Education, 2017). This strategy includes multiple references to climate change, and what people of all ages can do to take action. Achieving co-ordinated cross-sectoral action to fully realise the intentions of the strategy has proved difficult. However, the Ministry for the Environment has funded some activities, including partnering with the Science Learning Hub to produce a large suite of teaching and learning resources linked to the Our Atmosphere and Climate 2020 report (Ministry for the Environment and Stats NZ, 2020).

By international standards, New Zealand's diffuse educational response to climate change is not unusual. Across most nations, while climate-action policies may call for education to contribute substantially to addressing climate change, analyses suggest that education policies are often not aligned to this call (Bieler et al., 2017; UNESCO, 2019), and thus "the education sector remains underexploited as a strategic resource to mitigate and adapt to climate change" (UNESCO, 2015, p. 66).

In summary, while there are some levers and supports for New Zealand schools to actively engage in responding to climate change, the onus to take active steps in this direction currently appears to sit with individual schools, teachers, or students who choose- or do not choose- to make this a focus. New Zealand's decentralised network of self-managing schools allows for a significant level of autonomy, diversity, and creativity in the design and delivery of localised curriculum. School principals and boards of trustees also carry considerable responsibilities in relation to school property and operations. However, our surveys and interviews indicate that some people within education are looking for clearer signals about the significance of climate change "from the top". As one interviewee noted:

We tend to do a really good job in education of saying,

'We want to do this', and then it is just left to people to get there on their own. Not all schools are created equal. And in this instance, that's not going to be acceptable (Secondary educator, cited in Bolstad, 2020b) 


\section{What can educational responses to climate change look like?}

International models for "climate-ready" schooling (Chopin et al., 2018) identify the need for high-level strategic planning that weaves climate and sustainability thinking into all school practices, and decision making at every level. This includes engagement from school leadership and governance, as well as staff, students, and the wider school community.

Souza et al., (2019) describe two domains within which we can act with respect to climate change and sustainability: the "material" and the "immaterial". These can also be thought of as "things" and "ideas, knowledge, and ways" (Table 1). This is a useful starting point for considering the specific contributions that education can make towards a safe climate future.

TABLE 1. TWO DOMAINS OVER WHICH WE HAVE INFLUENCE

\begin{tabular}{|l|l|}
\hline Material "things" & $\begin{array}{l}\text { Our built world, the buildings, objects, } \\
\text { vehicles, materials, and products that we } \\
\text { use and consume, and waste products } \\
\text { we generate. }\end{array}$ \\
\hline $\begin{array}{l}\text { Immaterial } \\
\text { "Ideas, knowledge, } \\
\text { and ways" }\end{array}$ & $\begin{array}{l}\text { How we think, what we value, how we } \\
\text { act in the world. Our understanding of } \\
\text { the world, and visions and expectations } \\
\text { of how the world could be. }\end{array}$ \\
\hline
\end{tabular}

In the material domain, there are direct climate benefits to reducing the environmental footprint of our materials and infrastructure, and seeking more efficient, cleaner, and longer-lasting alternatives. The Sustainability Contestable Fund, discussed above, is one source of support for schools to implement sustainability initiatives such as installing solar panels, replacing inefficient heating systems, and removing coal boilers. New school builds provide opportunities for thinking in climate-smart ways (see Flexibility and Sustainability in School's New Build, 2020). Schools can also have a direct influence on living systems within or near the school grounds. Planting trees, restoring wetlands, maintaining food gardens, composting, worm farming, beekeeping, avoiding food waste, and building healthy soil all have climate-impact benefits, as well as presenting rich opportunities for student learning and engagement.

While direct emissions-reductions through changes to school infrastructure and operations are important, it is critical to keep students' learning opportunities at the centre of thinking. As well as being involved in sustainability improvements within the school, learning opportunities across the curriculum can help to support the development of knowledge, values, attitudes, and capabilities that people need to mitigate and adapt to climate change, and live sustainably on a planet with finite resources. It is also important to create space for reflection on "the deeper values and principles upon which people as individuals and as part of collectives are currently building their future" (Brouwer et al., 2016, cited in Souza et al., 2019, p. 1607), and "examine the degree to which existing education is adapted to, and prepares people for, radically different futures." (UNESCO, 2012, p. 8).

Our research, and other New Zealand and international research, highlights the role that schools can play in building community resilience, empowering and mobilising young people's creative and adaptive problemsolving capabilities, and supporting localised innovation in response to climate and sustainability knowledge. Finally, education in Aotearoa New Zealand can support students to engage with indigenous knowledge systems and mātauranga Māori, unpack the relationships between climate change and colonisation (Jones, 2019), and understand how Treaty of Waitangi principles and obligations can be upheld as Aotearoa New Zealand transitions to a low-emissions future (Bargh, 2019).

\section{What is currently happening in New Zealand schools?}

Other articles in this special issue illustrate what educational responses to climate change can look like in practice, across diverse learning contexts (see also Bolstad, 2020b). Our recent surveys of teachers and school leaders in English-medium schools also provide general insights into climate and sustainability thinking and practice across schools. Our surveys asked questions about school-wide focuses, climate change in the curriculum, classroom teaching and learning practices, and what impacts teachers and school leaders expect climate change will have in students' lifetimes.

\section{Caring for the environment is a common focus in primary schools}

Eighty-eight percent of primary and intermediate principals we surveyed in $2019^{14}$ indicated a school-wide focus on kaitiakitanga/care for the environment, and 83\% indicated a school-wide focus on reducing waste (see Figure 1). Seventy-eight percent said Enviroschools or student environmental or gardening projects were "well-embedded" or "partially embedded" in their school. These findings may reflect the success of nation-wide programmes including Enviroschools ${ }^{15}$ and other national, regional, and local programmes that support schools with gardening and sustainability initiatives. The 2019 survey did not specifically ask whether climate change was a school-wide focus in primary or intermediate schools, though we did ask teachers 
about classroom teaching and learning with respect to climate and sustainability (see Figure 3).

\section{School-wide focus on} sustainability and climate is less common in secondary schools

In contrast with primary/ intermediate schools, just $47 \%$ of teachers and leaders from Englishmedium secondary schools surveyed in $2020^{16}$ agreed that kaitiakitanga/ care for the environment was a school-wide focus (see Figure $2)$. About a third (32\%) said sustainability was a school-wide curriculum priority, and just $21 \%$ said climate change was a schoolwide curriculum priority. Very few (less than 5\%) strongly agreed that any of these were a priority. Some schools consider sustainability and climate change in operational and procurement decisions, while others do not. Cost, time, and buy-in were among the barriers to identifying and implementing operational and infrastructure improvements that would increase school sustainability and reduce climate emissions.

\section{Schools generally support student leadership in sustainability, environment, and climate}

While school-wide prioritisation may be low, particularly in secondary schools, support for student leadership and engagement in climate and sustainability seems to be relatively high (Figure 2). Many secondary/composite survey respondents said that their school has student-led climate, sustainability, or environmental groups (78\%), or that their school has environmental leaders or prefects (69\%). Many (70\%) indicated support for students who choose to take part in protests or

\section{FIGURE 1. SCHOOL-WIDE FOCUSES REPORTED BY PRIMARY AND} INTERMEDIATE PRINCIPALS, 2019 ( $\mathrm{N}=145)$

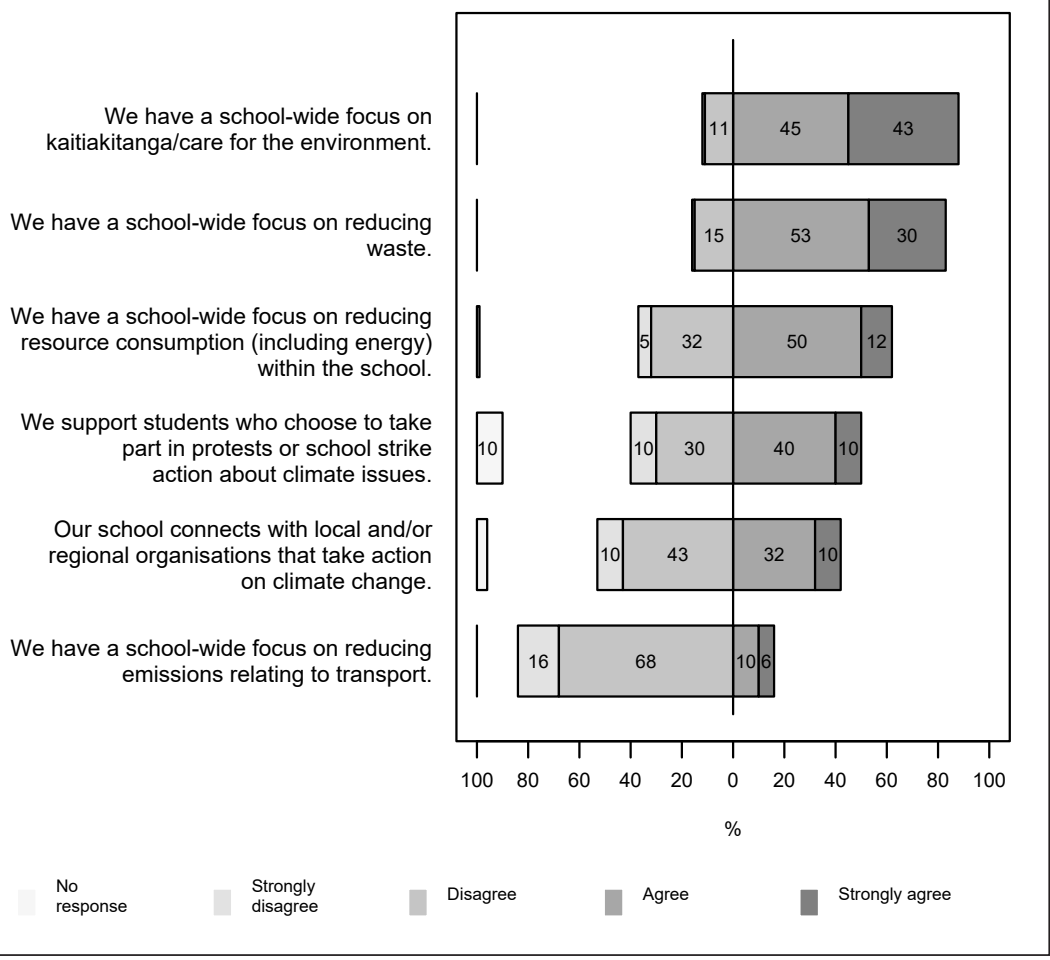

FIGURE 2. SCHOOL-WIDE FOCUSES REPORTED BY SECONDARY TEACHERS AND SCHOOL LEADERS $(\mathrm{N}=106)$

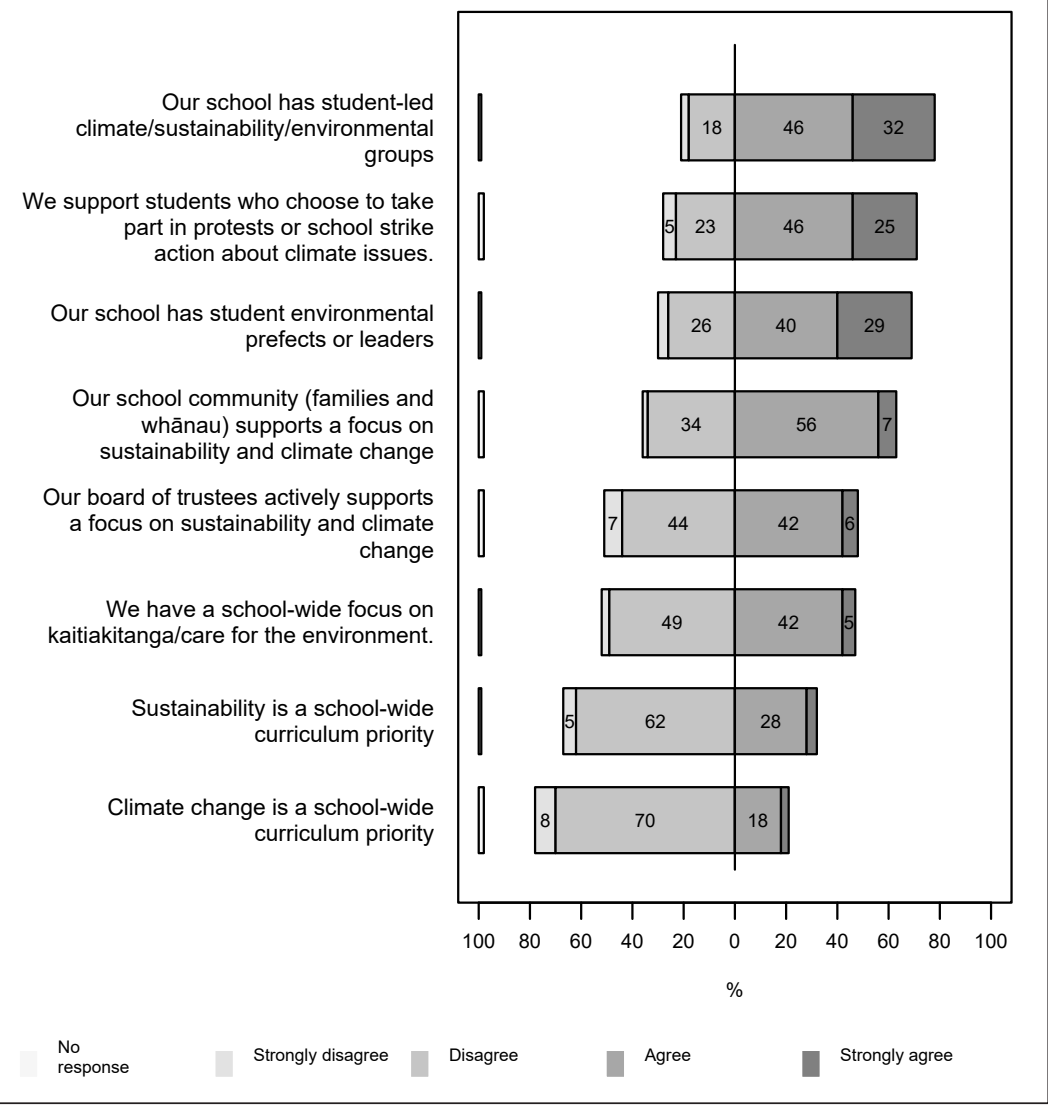




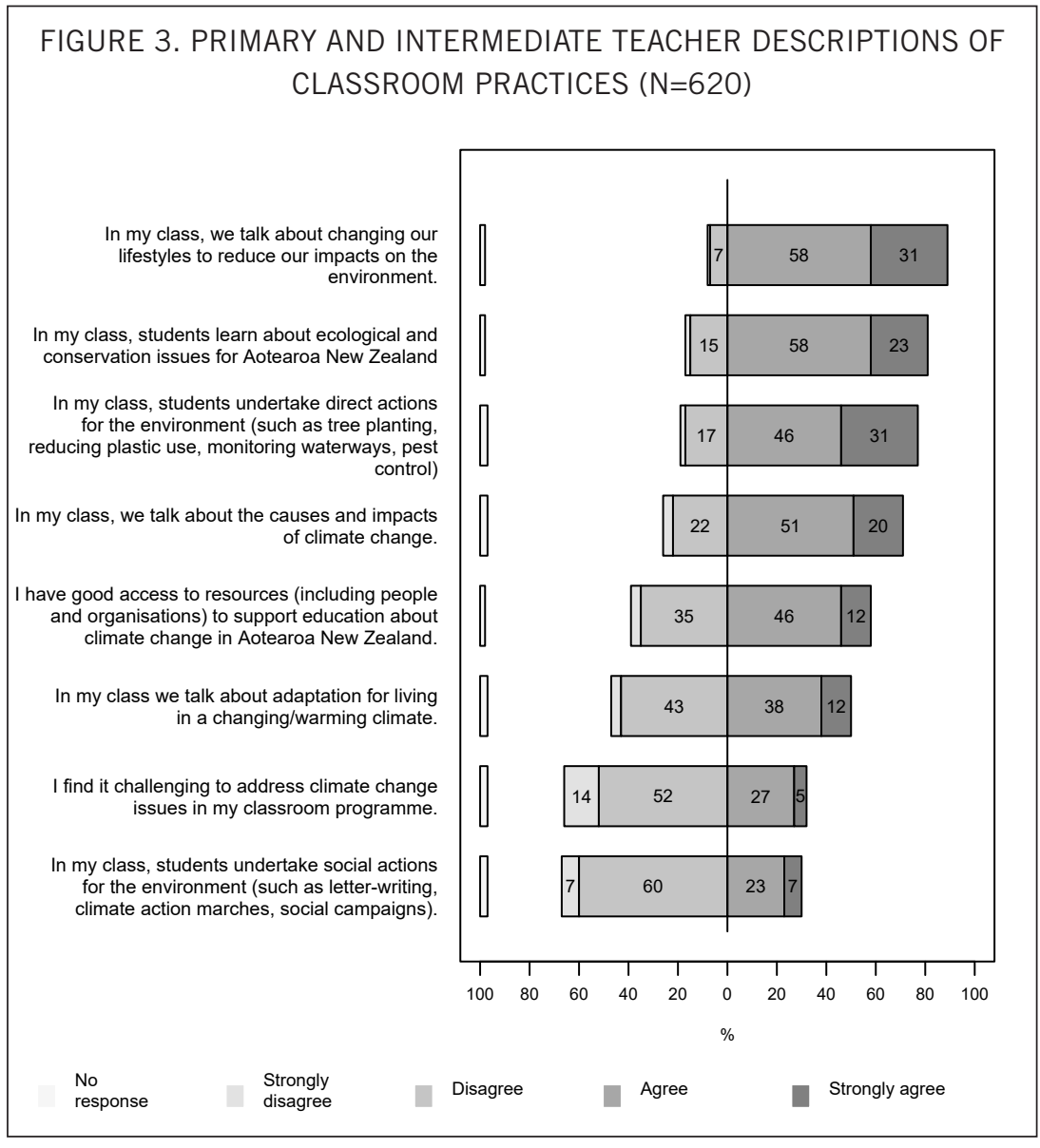

school-strike action. Primary-school principals were a little more divided about support for student climate strikes with 50\% agreeing, 40\% disagreeing, and $10 \%$ choosing not to answer the question. We speculate that primary principals' responses might reflect duty-of-care responsibilities for younger children who are absent from school. Some principals also cited concerns about young children bearing the emotional or psychological weight of climate change on their shoulders.

\section{Support from communities and boards of trustees is variable}

Just under two-thirds of secondary survey respondents indicated that their school community supports a focus on sustainability and climate change $(63 \%)$, though fewer than half (48\%) said their board of trustees actively supports such a focus. The patterns in the survey data raise some interesting questions. Do secondary schools tend to see climate, environment, and sustainability as something that students should lead, rather than seeing it as something that needs a whole-school strategy and plan? Do school principals, teachers, boards, and other adults in schools need more guidance on what effective climate and sustainability leadership can look like? And to what extent are students' learning opportunities enabled, or hindered, by a lack of school-wide or community engagement? Survey comments suggest a range of experiences.

[We] involve students in exploring concepts around climate change and deciding next steps for our school (Primary principal survey response, 2019)

[A focus in my classroom is] supporting students to present to the board, communicate with our community, run projects from feasibility to completion, and be actively involved in driving all school sustainability initiatives. (Secondary survey response, 2020)

Currently in the community a number of groups are trying to "future proof" the local environment. They often include younger children from local schools, but there is not necessarily much support from adults in the community. Some adults have been known to damage and destroy work that has been done by these groups and by local schoolchildren. (Secondary survey response, 2020)

\section{Causes/impacts, and personal actions, are often emphasised}

Both the primary and secondary surveys gathered information about classroom teaching and learning in relation to climate and sustainability. Among primary teachers surveyed in 2019, most said their class talked about "changing our lifestyles to reduce our impacts on the environment" (89\%), that students learnt about ecological and conservation issues for Aotearoa New Zealand (81\%), and that students undertook direct actions for the environment (77\%). Slightly fewer (71\%) said their classes talked about the causes and impacts of climate change, though the proportion was over $80 \%$ when only looking at teachers of Years 4 and above.

Most secondary teachers responding to the 2020 survey taught science or social science subjects, although we also had small numbers of responses from subjects in every learning area of the curriculum. We asked secondary teachers about 19 things that might be a focus for learning and teaching in relation to climate change (Table 2). 
The two most common focuses were personal actions that individuals can take to have a positive impact (84\%), and scientific knowledge about the causes and impacts of climate change (81\%).

\section{Solutions and student pathways are lesser focuses}

Of all the things we asked secondary teachers about, most were likely to say they were at least a "minor" focus. However, a few items in Table 2 were described by more than $20 \%$ of teachers as "not a focus". The least common, by a significant margin, was "students career options and pathways in a 'green' or 'transition to low emissions' economy”. This was either not a focus (31\%) or only a minor focus (42\%). Mātauranga Māori or other indigenous knowledges as sources for positive climate and sustainability action was "not a focus" for $21 \%$ of teachers; and $21 \%$ said specific impacts of climate change for Pacific peoples was "not a focus". A third (34\%) of teachers indicated a "minor" focus on critical or media literacy such as how to evaluate science evidence or media reporting about climate change, and $13 \%$ said this was "not a focus".

\section{Collective or systemic actions are less common than personal actions}

As shown in Table 3, personal/individual actions were more than twice as likely to be a "major focus" in secondary classrooms than collective, local/regional, and systemic actions.

The significant focus on personal action over other forms of collective and systemic action could be interpreted as both a strength and a shortcoming. Interpreted as a strength, this could indicate that teaching approaches are geared towards supporting students to understand climate change not as just an abstract and distant idea, but a matter that has personal relevance and connection, and over which they have some degree of agency and control. Focusing on personal action can also highlight the ways in which individual consumer choices and citizen actions can collectively add up to have significant climate and environmental impacts. Finally, mental wellbeing can be enhanced when people feel that they can take action, and their actions make a difference.

However, a focus on personal action can also obscure wider collective and systemic causes. Putting the responsibility on consumers and citizens to make better choices can remove responsibilities from those who benefit from unsustainable modes of production. The "personal action" focus may also gloss over other kinds of inequities. For example, peoples' choices may be constrained by social, economic, geographic, or cultural factors beyond their control.
TABLE 2. SECONDARY CLASSROOM TEACHING AND LEARNING FOCUS $(\mathrm{N}=67)$

$\%$

Moderate or major focus

Personal actions - things we can do as individuals to have a positive impact

Scientific knowledge about the causes and impacts of climate change

Impacts of climate change on human health and wellbeing

Discussion about whether climate change is

caused by humans, and/or whether it is a global crisis

Specific impacts of climate change for Aotearoa New Zealand

Impacts of climate change for nonhuman species

How students are feeling about climate change

Scientific and technological innovations that reduce the impacts of climate change

Specific impacts of climate change for our region/ local area

Things we can do collectively as a school and community to have a positive impact

Systemic actions-things that governments can do to address climate change

Interconnections between different systems in relation to climate change

Social inequalities and social justice-how different people/groups will be impacted by climate change

Specific impacts of climate change for Pacific peoples

Adaptation or mitigation activities that are underway in our region/local area

Economic impacts of climate change

Critical literacy or media literacy-how to evaluate science evidence or media reporting

Mātauranga Māori, and/or other indigenous

knowledge and practices, as sources for positive

climate and sustainability action

Students' career options and vocational pathways in a "green" or "transition to low-emissions" economy

TABLE 3. LEVELS OF ACTION SECONDARY LEARNERS MIGHT ENGAGE WITH $(\mathrm{N}=67)$

Personal actions - things we can do as individuals to have a positive impact

Things we can do collectively as a school and community to have a positive impact

Adaptation or mitigation activities that are underway in our region/local area

Systemic actions - thing governments can do to address climate change

$\%$
Major
focus
57
25
22
21


At a school level, teachers and students may find it easier to focus on personal choices or actions they can take within their classroom or personal lives, rather than taking on collective school-wide actions, or wider regional, community, or national-level actions. Such actions often involve longer timeframes, sustained advocacy, and require a broader base of support from people in positions of power to have a tangible impact. Nevertheless, our research and other literature has identified a range of examples where students and young people have been involved in collective actions or advocacy for actions at school, regional, and national levels. ${ }^{17} \mathrm{~A}$ recurring theme in these contexts is that learners are supported by adults who value young people's contributions, and can provide enabling support and sustained connections over time, both within and beyond the school. However, some teachers describe constraints on what they, or their students, can take on, including from a time and wellbeing perspective.

We have limited time to cover so many vital issues. We have been focussing on positive themes due to developing anxiety and wellbeing around our students. The problem we have been facing is that so much needs to be done across so many areas and we only have limited time. (Secondary teacher survey respondent, 2020)

\section{Teachers and school leaders expect climate change will impact their students' lives}

More than $75 \%$ of teachers and school leaders we surveyed in English-medium primary/intermediate and secondary/ composite schools expect climate change will have at least "moderate" impacts within their students' lifetimes. More than half expect "major" impacts (Bolstad, 2020a; forthcoming). Our most recent survey asked secondary/ composite teachers and school leaders about a range of potential impacts - both negative and positive. While it is generally understood that climate change will have many negative impacts, asking about positive impacts acknowledges that how climate change will affect us depends in part on how we (regionally, nationally, and globally) plan, prepare, and respond. It also acknowledges that there are opportunities for people to act now to shape our shared futures in positive ways. The survey responses suggest varying degrees of optimism, particularly with regards to positive social and cultural impacts. (For details, see Bolstad, 2020c).

While some students and teachers we have interviewed have encountered "climate denial" among teachers in their schools, our survey data suggests this is probably a minority view. However, some respondents across all our surveys didn't seem to think climate change was much of a concern, and our data suggests that even if educators are concerned about climate change, this doesn't necessarily mean it will be a focus in the curriculum or across the school.

\section{Teachers identified resources and PLD that would support their practice}

More than half of the secondary teachers (64\%) said they didn't have good access to PLD to support their teaching in relation to climate change. A few teachers commented about the value of seeing a list of New Zealand learning and teaching resources in the survey.

It's great to see all of these resources, many of which I didn't know and so having PD around this could be really valuable. (Secondary teacher survey respondent, 2020)

Teachers also had resource gaps and "wishlists", for example:

A tool to measure their carbon footprint that is relevant to $\mathrm{NZ}$ students and their lives, and includes ways to reduce their emissions. (Secondary teacher survey respondent, 2020)

I have identified a lack of educational resources around regenerative agriculture and local food systems. (Secondary teacher survey respondent, 2020)

Resources based around tikanga and mātauranga. (Secondary teacher survey respondent, 2020)

Having access to experts and networks of people and support was also mentioned as useful for both students and teachers.

More access to climate scientists to come and answer students' questions. More access to city councillors to explain the work they are doing/the planning they are doing to prepare for the future of [our city] in terms of climate resilience. (Secondary teacher survey respondent, 2020)

\section{Where to from here?}

Our research indicates there is scope for growth and development in the way that schools and the wider education system in Aotearoa New Zealand respond to climate change. In-depth interviews we have carried out as part of our research (Bolstad, 2020b) highlighted key things schools can focus on, including:

- Supporting diverse children and young people to develop their ideas and visions for a sustainable future, and to identify actions they can take to realise that future.

- Involving children and young people in collective and local approaches, and community-wide responses to climate change.

- Scaffolding learners to ensure that they build key knowledge, as well as developing ethical thinking, systems thinking, and critical thinking.

- Focusing on new career opportunities and pathways in an economic transition to a low-carbon, changed climate future. 


\section{NATIONAL OVERVIEW}

- Getting children and young people engaged and excited about what they can do, rather than disengaged, depressed, or feeling like they have no control of their future.

Effective responses to climate change are also affected by wider systems, societal and political structures, norms, and mindsets. The relatively low visibility of climate change in current educational policy and strategy frameworks may send a signal that this is a low priority for the education sector. However, system changes on the horizon, both within and beyond education, could provide new leverage for change. Within education, plans around the reforms of Tomorrow's Schools (Ministry of Education, 2019) could generate opportunities for more coherent system-wide educational response to climate change, through reorganising responsibilities around school property, devising new processes for updating the national curriculum, and deepening schools' capabilities to give effect to Te Tiriti o Waitangi. Proactive climate strategy responses emerging within education sector organisations such as NZEI also show what effective sector leadership can look like. Looking more widely, in February 2021 New Zealand's new Climate Commission will release its advice for what climate action could look like in Aotearoa New Zealand in 2021 and beyond. As New Zealand works to set targets and monitor our progress against our global climate obligations there will be implications for all sectors. As educators, we must ensure there is a continued focus on what roles education can play, and advocate for supports that help schools do their part.

\section{Notes}

I. For details, see the website of the Intergovernmental Panel on Climate Change (IPCC) https://www.ipcc.ch/

2. Scientists estimate anthropogenic activities have led to a $+\mathrm{I}$ degree average temperature rise since preindustrial times, and Earth will experience continued warming effects from existing atmospheric GHG. The current global goal is to limit further rise to +I.5 degrees, but success in meeting this goal is not certain and is highly dependent on global actions in the next few years.

3. The UNFCCC was developed in 1992, ratified by New Zealand in September 1993, and entered into force on 2I March 1994. As of December 2015, UNFCCC had 197 parties, including all United Nations member states.

4. See https://unfccc.int/process-and-meetings/the-parisagreement/what-is-the-paris-agreement

5. See http://www.legislation.govt.nz/act/public/2019/006I/ latest/LMSi83736.html

6. See https://unfccc.int/topics/education-and-outreach/ workstreams/education-and-training

7. The Toimata Foundation receives partial funding from the Ministry for the Environment.
8. See https://www.education.govt.nz/school/funding-andfinancials/funding/sustainability-contestable-fund/

9. https://nzcurriculum.tki.org.nz/News/Climate-ChangeLearning-Programme-Teacher-Resource. See Eames et al., 2020, for a review of the Climate Change Learning Programme).

Io. See https://putatara.education.govt.nz/\#/home

II. See https://www.education.govt.nz/our-work/overallstrategies-and-policies/

I2. The "future-focus" principle in The New Zealand Curriculum (2007) says "The curriculum encourages students to look to the future by exploring such significant future-focused issues as sustainability, citizenship, enterprise, and globalisation".

I3. The strategy development was led by the Department of Conservation with involvement of the Ministry for the Environment and the Ministry of Education.

I4. The 2019 NZCER National Survey of Primary and Intermediate Schools was sent to went to a representative sample of 350 English-medium primary and intermediate schools. There was one survey for principals and another survey for teachers, with schools asked to randomly sample eight teachers to complete the survey. Responses were received from 145 principals, and 620 teachers from I8I schools.

I5. See https://enviroschools.org.nz/your-region/

I6. In 2020 we sampled I49 secondary and composite schools that teach students in Years 9 and above, and invited schools to return three surveys, at least one from a school leader, and at least two from teachers in different learning areas that include a focus on sustainability or climate change. We received 106 responses from 60 schools. Some questions were asked of all respondents, and some were filtered by participants previous responses, including questions about their roles and responsibilities in their school, and whether climate change was explicitly addressed in classes they teach.

I7. Prominent national examples include Generation Zero, a youth-led climate action organisation that played a significant role in advocacy and campaigning for the Zero Carbon Act, and the organisation of the School Strikes for Climate marches.

\section{References}

Bargh, M. (2019). A tika transition. In D. Hall (Ed.), A careful revolution: Towards a low-emissions future (pp. 9-16). Bridget Williams Books. https://doi.org/10.7810/9781988545684_2

Bieler, A., Haluza-Delay, R., Dale, A., \& McKenzie, M. (2017). A national overview of climate change education policy: Policy coherence between subnational climate and education policies in Canada (K-12). Journal of Education for Sustainable Development, 11(2), 63-85.

Bolstad, R. (2020a). Climate change and sustainability in primary and intermediate schools: Findings from the 2019 NZCER 


\section{NATIONAL OVERVIEW}

national survey of English-medium schools. New Zealand Council for Educational Research. https://www.nzcer.org. $\mathrm{nz} /$ research/publications/climate-change-and-sustainabilityprimary-and-intermediate-schools

Bolstad, R. (2020b). Opportunities for education in a changing climate: Themes from key informant interviews. New Zealand Council for Educational Research. https://www.nzcer.org.nz/research/publications/opportunitieseducation-changing-climate-themes-key-informant-interviews

Bolstad, R. (2020c). Climate change and sustainability in secondary schools: Findings from a 2020 survey of Englishmedium secondary and composite schools. New Zealand Council for Educational Research.

Chopin, N., Hargis, K., \& McKenzie, M. (2018). Building climate-ready schools in Canada: Towards identifying good practices in climate change education. Sustainability and Education Policy Network, University of Saskatchewan, Saskatoon, Canada. https://sepn.ca/resources/report-buildingclimate-ready-schools-canada/

Department of Conservation, Ministry for the Environment, and Ministry of Education (2017). Mãtauranga whakauka taiao: Environmental education for sustainability. Mahere rautaki strategy and action plan 2017-2021. Department of Conservation: Wellington. https://www.doc.govt.nz/about-us/ our-policies-and-plans/education-strategies/environmentaleducation-for-sustainability-strategy-and-action-plan/strategyand-action-plan-20172021/

Eames, C., Ritchie, J., Birdsall, S., and Milligan, A. (2020). Climate change: Prepare today, live well tomorrow-A review. Set: Research Information for Teachers, (3). https://doi. org/10.18296/set.0185

Flexibility and sustainability in school's new build. (2020). Education Gazette Tukutuku Körero, 99(17), 2-5.

IAG. (2020). Climate change survey results 2018-2020. https:// www.iag.co.nz/latest-news/articles/Climate-poll-2020.html

Jones, R. (2019). Climate change and indigenous health promotion. IUHPE - Global Health Promotion, 26 (Supp. 3). https://doi.org/10.1177/1757975919829713

Leining, C., \& White, S. (2015). From fact to act: New Zealanders' beliefs and actions on climate change (Motu Note \#19). Motu Economic and Public Policy Research.
Ministry for the Environment. (2017). New Zealand's seventh national communication -Fulfilling reporting requirements under the United Nations framework convention on climate change and the Kyoto protocol. Ministry for the Environment.

Ministry for the Environment, \& Stats NZ. (2020). Our atmosphere and climate 2020. Ministry for the Environment \& Stats NZ. https://www.mfe.govt.nz/publications/ environmental-reporting/our-atmosphere-and-climate-2020

Ministry of Education. (2007). The New Zealand curriculum. Learning Media.

Ministry of Education. (2018). International education strategy: He rautaki mätauranga a ao. Author.

Ministry of Education. (2019). Supporting all schools to succeed. Reform of the Tomorrow's Schools system. https://conversation. education.govt.nz/conversations/tomorrows-schools-review/

Ministry of Education. (2020a). Te rautaki rawa kura: The school property strategy 2030. Author.

Ministry of Education. (2020b). Action plan for Pacific education 2020-2030. Author.

Souza, D. T., Wals, A. E. J., \& Jacobi, P. R. (2019). Learningbased transformations towards sustainability: A relational approach based on Humberto Maturana and Paulo Freire. Environmental Education Research, 25(11), 1605-1619. https:// doi.org/10.1080/13504622.2019.1641183

UNESCO. (2012). Education sector responses to climate change. https://unesdoc.unesco.org/ark:/48223/pf0000215305

UNESCO. (2015). Not just hot air: Putting climate change education into practice. Author.

UNESCO. (2019). Country progress on climate change education, training and public awareness: An analysis of country submissions under the United Nations framework convention on climate change. Author.

United Nations (1992). United Nations framework convention on climate change. United Nations, General Assembly. https:// unfccc.int/resource/docs/convkp/conveng.pdf

Rachel Bolstad is a senior researcher at the New Zealand Council for Educational Research Email: Rachel.Bolstad@nzcer.org.nz 